\title{
Impact of Accompanying Comorbidities on Survival in Patients with Stage IIIB- IV Non-Small-Cell Lung Cancer
}

\author{
Mustafa DEMIRPENCE ${ }^{1}$, Tulay AKMAN², Ilhan OZTOP², Ilkay T. UNEK ${ }^{2}$, \\ Tugba YAVUZSEN ${ }^{3}$, Ahmet U. YILMAZ ${ }^{4}$ \\ ${ }^{1}$ Tepecik Training and Research Hospital, Department of Internal Medicine, \\ ${ }^{2}$ Tepecik Training and Research Hospital, Division of Medical Oncology \\ ${ }^{3}$ Dokuz Eylul University, Faculty of Medicine, Department of Medical Oncology \\ ${ }^{4}$ Izmir University, Medical Park Hospital, Division of Medical Oncology, Izmir,TURKEY
}

\begin{abstract}
The aim of the study was to investigate the impact of accompanying comorbidities on survival in non-small-cell lung carcinoma (NSCLC) patients. A total of 221 patients with stage IIIB- IV NSLC between May 1998 and April 2009 were included. Survival data was analyzed according to age (those younger than 65 and those 65 and older) and Charlson Comorbidity Index (CCl) scores. Eighty-six (39\%) patients were aged 65 and older, and the remaining 135 (61\%) were younger than 65. In the 65 and over group the median survival of patients was 44 months for CCl Group 0, 16 months for CCl Group 1, 10 months for CCl Group 2, and 10 months for CCl Group 3. For the younger group, the median survival time was 19 months for CCl Group 0, 18 months for CCl Group 1, 11 months for CCI Group 2, and 11 months for $\mathrm{CCl}$ Group 3. There were no statistically significant differences in the comorbidity factors regarding survival in the two groups of patients. In conclusion, the frequency of comorbidity factors increased in stage IIIB and IV NSCLC patients as age increased. Although survival in patients with higher $\mathrm{CCl}$ scores was shorter, the CCl was not associated with survival for patients having local advanced and metastatic disease; no significant difference was found statistically for these patients. Therefore, these patients need to be managed more thoroughly.
\end{abstract}

Keywords: Locally advanced and metastatic Non-small-cell lung carcinoma, Charlson Comorbidity Index, Survival

\section{ÖZET}

Evre IIIB-IV Küçük Hücre Dışı Akciğer Kanseri Hastalarında Eşlik Eden Komobiditelerin Sağkalım Üzerine Etkisi

Bu çalışmanın amacı Küçük Hücreli Dışı Akciğer Kanserli (KHDAK) hastalarda komorbid faktörlerin sağkalım üzerine olan etkisinin araştııımasıdır. Mayıs 1998 ile Nisan 2009 tarihleri arasında, histopatolojik olarak KHDAK tanısı almış, evre IIIB ve IV olan toplam 221 hasta çalışmaya alınmıştır. Sağkalım verileri yaşa (65 yaş ve üstü ve 65 yaş altı) ve Charıson Komorbidite İndeksine (CKI) göre değerlendirildi. 86 hasta (\%39) 65 ve üzeri yaşta, geri kalan 135 (\%61) hasta 65 yaşından az idi. 65 yaş ve üzeri grupta CKi'ye göre değerlendirildiğinde median sağkalım Grup 0 için 44 ay, Grup 1 için 16 ay, Grup 2 için 10 ay, Grup 3 için 10 ay olarak saptandı. Genş yaştaki grupta, median sağkalım Grup 0 için 19 ay, Grup 1 için 18 ay, Grup 2 için 11 ay, Grup 3 için 11 ay olarak saptandı. İki grup arasında sağkalımı etkileyen komorbit faktörler değerlendirildiğinde istatiksel anlamlı farkllık saptanmadı. Sonuç olarak, Evre IIIB ve IV KHDAK hastalarda yaş arttıkça komorbid faktörlerin sıkığının arttığı ancak yaş bakımından sağkalımda anlamlı bir fark olmadığı saptanmıştır. Charlson Komorbidite Indeks skorları yüksek olanlarda sağkalımın kısa olması bu hastalara daha titizlikle yaklaşılmasını gerektirmektedir.

Anahtar Kelimeler: Küçük hücreli dışı akciğer kanseri, Charlson komorbidite indeks 


\section{INTRODUCTION}

Lung carcinoma is still the most common and lethal cancer in the world. ${ }^{1}$ Each year approximately 1.2 million new cases are diagnosed. The rise in developing countries may be attributely in part due to the availability of cigarettes and lack of environmental regulations. Small-cell lung carcinoma (SCLC) comprises approximately $15-20 \%$ of all lung cancers. The remainder are due to non-small-cell lung carcinoma (NSCLC). ${ }^{1}$ Most of the patients with NSCLC are in an advanced stage of cancer at the time of diagnosis The prognosis is poor for these patients. Even in patients diagnosed at earlier stages, distant metastases develop in $40-70 \%$ of cases during the course of the disease in spite of surgical resection. ${ }^{2}$ In advanced stage NSCLC, the initial therapy involves systemic treatment and radiotherapy in selected cases. Surgery is performed only if necessary and for palliative reasons. Chemotherapy augments the survival and increases the life quality in NSCLC patients in the advanced stages. ${ }^{3}$ Performance status, weight loss, gender, and degree of penetration of the disease are defined as the leading prognostic factors affecting survival in advanced stage diseases.

Lung carcinoma is more common in the elderly and has a close correlation with cigarette smoking. As a result, the comorbidities encountered in elderly populations and smokers usually accompany lung cancer, which narrows treatment options and requires changes to be made in therapeutic dose and duration in select circumstances. The scarcity of reports investigating the correlation between lung carcinoma and comorbidity in the literature is shocking. ${ }^{4-6}$ In clinical studies conducted previously, patients with significant comorbidities were generally excluded inthe study and, as a result, the effect of comorbidities on survival has never been truly evaluated. The most commonly used comorbidity evaluation methods for patients with cancer are the Charlson Comorbidity Index $(\mathrm{CCI})^{7}$, the Cumulative Illness Rating Scale (CIRS) ${ }^{8}$, the Index of Coexistent Disease (ICED) ${ }^{9-10}$ and the KaplanFeinstein Comorbidity Index..$^{11}$ The CCI is a comorbidity evaluation method designed by Charlson in 1987 that uses the data of patients admitted to the internal medicine ward. Analyses on the effect of various comorbidity factors on one-year mortality have been carried out, and 18 comorbidity factors have been accepted as being relative risks for causing death. Other comorbidity indices have also been suggested; however, the CCI has still been found to be more reliable compared to other methods, especially in older patient groups and in those with expected life durations of less than a year. ${ }^{12-13}$

The aim of this study was to investigate the effects of comorbidity factors on survival in NSCLC patients younger than 65 years old and in those age 65 years of age or older who have stage IIIB and stage IV cancer.

\section{PATIENTS AND METHODS}

A total of 221 patients who were treated and followed up at the Dokuz Eylül University Medical Faculty Medical Oncology Department between May 1998 and April 2009 and who were diagnosed as having NSCLC histopathologically with stages IIIB and IV cancer were included in this study. All patient files were scanned retrospectively. All data regarding the age and gender of the patients, history of cigarette smoking, date of diagnosis, method of diagnosis, histologic type and stage of the tumor, performance status according to the Eastern Cooperative Oncology Group (ECOG), surgical therapy, radiotherapy, and chemotherapy were recorded.

The comorbidity status of the patients was evaluated according to the Charlson Comorbidity Index (CCI). ${ }^{7}$ The Charlson comorbidity index predicts the ten-year mortality for a patient who may have a range of comorbid conditions, such as heart disease, AIDS, or cancer; in total 22 conditions are evaluated by the index. A score of 1, 2, 3, or 6, is assigned to each condition depending on the associated risk of dying. Scores are summed to provide a total score to predict mortality. Clinical conditions and associated scores are as follows:

- 1 point each: Myocardial infarct, congestive heart failure, peripheral vascular disease, dementia, cerebrovascular disease, chronic lung disease, connective tissue disease, ulcer, chronic liver disease, diabetes.

- 2 points each: Hemiplegia, moderate or severe kidney disease, diabetes with end organ damage, tumor, leukemia, lymphoma.

- 3 points each: Moderate or severe liver disease.

- 6 points each: Malignant tumor, metastasis, AIDS. 
The CCI scores of the patients varied between 0 (no comorbidity) and 10 (maximum comorbidity). Patients were divided into four groups by their CCI scores with 0 points representing CCI Group 0, 1-2 points representing CCI Group 1, 3-4 points representing CCI Group 2, and 5 or more points representing CCI Group 3. ${ }^{7}$

The efficiency of therapies were evaluated by taking into account the parameters of response rate and survival. Response and toxicity evaluations were carried out according to the criteria described by the World Health Organization (WHO). In survival analyses, progression free survival (PFS) is accepted as the time from diagnosis until the time progression is encountered. Overall survival (OS) is taken as the time elapsed from diagnosis until the demise of the patient.

Patients were divided into two groups; one group was comprised of those age of 65 years and older and the other group were under the age of 65 years. The two groups were compared using the means of the previously described parameters. Local ethics committee approval was obtained from the Dokuz Eylul University Medical Faculty.

Statistical analyses of the obtained parameters were performed by SPSS 11.0 for Windows (SPSS Inc., Chicago, Illinois, USA). In the statistical evaluations, values related to constant variables were given as median \pm standard deviation, and values related to qualitative variables were given as per-

\begin{tabular}{|lll|}
\hline Table 1. Patients' characteristics & & \\
\hline Parameters & $\mathbf{n}$ & $\%$ \\
\hline & & \\
Age & & \\
$\quad$ (Median, range) & & 61 (40-82) \\
$\quad \geq 65$ & 86 & 39.0 \\
$\quad<65$ & 135 & 61.0 \\
Gender & & \\
$\quad$ Male & 199 & 90.0 \\
Female & 22 & 10.0 \\
History of cigarette smoking & & \\
$\quad$ Yes & 200 & 90.5 \\
$\quad$ No & 21 & 9.5 \\
Tumor histology & & \\
Squamous cell carcinoma & 89 & 40.3 \\
Adenocarcinoma & 75 & 34.0 \\
Adenosquamous cell carcinoma & 48 & 21.7 \\
Large cell carcinoma & 8 & 3.2 \\
Bronchoalveolar carcinoma & 1 & 0.8 \\
Stage & & \\
IIIB & 95 & 42.1 \\
IV & 126 & 57.9 \\
\hline
\end{tabular}

centages. All survival and time survival curves belonging to PFS durations were constructed using the Kaplan-Meier method. Differences between the survival rates were evaluated with a log rank test with $\mathrm{p}<0.05$ accepted as being statistically significant. Independent comparisons within the groups

\begin{tabular}{|llll|}
\hline Table 2. Comorbidity according to age $>65$ & & \\
\hline Comorbidity & All patient groups & $\mathbf{< 6}$ (age) & $\mathbf{2 5}$ ( age) \\
& $\mathbf{( \% )}$ & $\mathbf{( \% )}$ & $\mathbf{( \% )}$ \\
\hline Chronic pulmonary disease & 31.2 & 26.7 & 38.4 \\
DM (without complications) & 24.4 & 20.8 & 30.3 \\
Coronary heart disease & 14.9 & 8.9 & 24.4 \\
Moderate and severe kidney disease & 12.2 & 9.6 & 16.3 \\
Other malignities & 11.8 & 10.4 & 14.0 \\
Peptic ulcus & 8.6 & 5.2 & 14.0 \\
Cerebrovascular disease & 5.9 & 3.7 & 9.3 \\
Peripheral vascular disease & 4.5 & 5.2 & 3.5 \\
Congestive heart failure & 3.6 & 2.2 & 5.8 \\
Connective tissue disease & 3.2 & 3.0 & 3.5 \\
Moderate-severe liver disease & 1.8 & 3.0 & 0.0 \\
Dementia & 0.9 & 0.0 & 2.3 \\
Hemiplegia & 0.9 & 0.7 & 1.2 \\
\hline
\end{tabular}


were performed by employing the Kruskal-Wallis test, independent samples (t-tests), and chi-square test methods. Statistical significance was achieved when $\mathrm{p}<0.05$.

\section{RESULTS}

\section{Patient Characteristics}

Of the 221 patients in the study, 199 (90\%) were male and $22(10 \%)$ were female. The median age was 61.23 (range 40-82). There were 135 (61\%) patients under the age of 65 and $86(39 \%)$ patients were 65 years old or older. The cigarette smoking rate was $90.5 \%$ in all patient groups, and it was more frequent in men $(95 \%)$ than in women $(47 \%)$. One hundred and forty-three $(64.7 \%)$ patients had an ECOG performance status of Grade 0, 51 (23.1\%) were Grade 1, 13 (5.9\%) were Grade 2, and $14(6.3 \%)$ were Grade 3. Stage IV disease was seen in $126(57.9 \%)$ patients, and $95(42.1 \%)$ patients had stage IIIB disease. The most common histologic type encountered was squamous cell carcinoma ( 89 patients, $40.3 \%$ ). The demographic data of the patients in the study is summarized in Table 1.

\section{Comorbidities and CCI}

In $86 \%$ of the patients aged 65 and over, there was at least one comorbid factor present; this ratio was $62 \%$ in the younger group. Comorbidities such as chronic lung disease (38.4\%), diabetes (30.3\%), and coronary heart disease $(24.4 \%)$ were more common in the older group whereas in the patient group under 65 years of age, comorbidities such as chronic lung disease (26.7\%), diabetes (17.8\%), and chronic kidney disease $(9.6 \%)$ were more prevalent (Table 2).

When the patients were evaluated with regard to the CCI groups, in the group aged 65 and over, there were $12(14 \%)$ patients in CCI Group 0, $51(59.3 \%)$ in CCI Group 1, 21 (11.6\%) in CCI Group 2, and $13(15.1 \%)$ in CCI Group 3. In the younger group, there were $50(37.3 \%)$ patients in CCI Group 0, 62 $(45.9 \%)$ in CCI Group 1, 17 (12.6\%) in CCI Group 2, and six (4.4\%) patients in CCI Group 3.

\section{Therapies}

Radiotherapy was given to $67.4 \%$ of all patients. Radical radiotherapy was performed on $28.9 \%$ of stage IIIB patients, and palliative radiotherapy given to stage IV patients, which made up the majority of the remaining $37.5 \%$.

Systemic chemotherapy was given to $90 \%$ of all patients. A single chemotherapy treatment line was given to 199 (90\%) patients whereas 103 (46.6\%) patients received multiple chemotherapy treatment lines and 24 (10.8\%) received three or more chemotherapy treatment lines. The median number of chemotherapy cycles given to patients was 3.6 with platinum/gemcitabine combination adminstered as the most common first line therapy regimen administered. (54.6\%). Docetaxel monotherapy was most often chosen as the second line chemotherapy option $(43.2 \%)$. In the distribution of chemotherapy options between the older and younger patient groups, 78 out of the 86 patients aged 65 and over (90.6\%) had systemic chemotherapy. Seventy-eight $(90.6 \%)$ patients used one chemotherapy treatment line, $37(43 \%)$ used two chemotherapy treatment lines, and seven (8\%) used at least three chemotherapy treatment lines. The median number of chemotherapy cycles given to the patients was 3.4. In the older age group, the most common chemotherapy regimen administered as the first line was a platinum/gemcitabine combination. Docetaxel monotherapy was the second leading choice, followed by vinorelbine monotherapy. In the group comprised of patients under 65 years old, 121 of the 135 patients (80.6\%) had systemic chemotherapy, $121(80.6 \%)$ used one chemotherapy treatment line, $66(54.5 \%)$ used two chemotherapy treatment lines, and 17 (14\%) used three or more chemotherapy treatment lines. The median number of chemotherapy cycles given to patients was 3.7. In the younger group, the most common chemotherapy regimen administered as the first line was the same platinum/gemcitabine combination with docetaxel monotherapy and vinorelbine monotherapy representing the next two most popular treatment options, which was the same as with the older group of patients. Compared to the 65 years and over age group who received the platinum/gemcitabine combination at a rate of $73.3 \%$, the patients in the younger group received it at a more frequent rate of $88.1 \%$. Monotherapy (chemotherapy with one medication) was preferred more then combination therapy (two chemotherapy medications are combined) for the the group with patients over 65 years of age than the younger group (17.4\% versus $1.5 \%$, respectively). 


\begin{tabular}{|c|c|c|c|c|}
\hline \multirow[b]{2}{*}{ Toxicities } & \multicolumn{2}{|c|}{$\mathrm{CCl}$ Groups 0 and 1} & \multicolumn{2}{|c|}{ CCI Groups 2 and 3} \\
\hline & Grade 3 (\%) & Grade 4 (\%) & Grade $3(\%)$ & Grade 4 (\%) \\
\hline \multicolumn{5}{|c|}{ First chemotherapy bout } \\
\hline Hematologic & 12 & 17 & 14 & 17 \\
\hline Non-hematologic & 14 & 7 & 16 & 24 \\
\hline \multicolumn{5}{|c|}{ Second chemotherapy bout } \\
\hline Hematologic & 12 & 10 & 19 & 19 \\
\hline Non-hematologic & 8 & 3 & 14 & 9 \\
\hline
\end{tabular}

\section{Toxicity}

When the grade 3-4 toxicities encountered during the chemotherapy regimens were assessed for both patient groups, the percentage of hematologic and non-hematologic toxicities, after the first line chemotherapy regimen, were $27.9 \%$, and $30.1 \%$, respectively. After the second chemotherapy regimen, these percentages declined slightly to $20.8 \%$ and $13.1 \%$. (Table 3 ) When an evaluation of toxicities was made after the first chemotherapy regimen in the patients aged 65 and over, the most common grade 3-4 hematologic and non-hematologic toxicities were seen in $21.8 \%$ and $19.7 \%$ of these patients, respectively. In contrast, in those patients under the age of 65 , these toxicities were seen at rates of $30.8 \%$ and $19.7 \%$.

After the second chemotherapy regimen in the patient group aged 65 and over, the most common grade 3-4 hematologic toxicity rate was $27 \%$ while the rate for non-hematologic toxicities was $15.6 \%$. For the younger group, the same toxicities were ob- served in $18.7 \%$ and $11 \%$ of the patients, respectively. When these toxicities were categorized by CCI groups, patients belonging to CCI groups 2 and 3 had higher toxicity levels than those in CCI groups 0 and 1 (hematologic toxicity 31\% versus 29\%, respecively; non-hematologic toxicity $40 \%$ versus $21 \%$, respectively) (Table 3 ).

The CCI groups were evaluated with reference to two categories for toxicity according to the two age groups. In patients belonging to CCI Groups 2 and 3 , there were more grade 3-4 hematologic and nonhematologic toxicities in the older age group than the younger age group, with a hematologic toxicity for those 65 and older of $23.8 \%$ versus $18.7 \%$ for those under 65 years old. This was in conjunction with non-hematologic toxicity levels of $18.7 \%$ for the older group versus $12.5 \%$ for the younger patients. However, the toxicity distribution was similar in patients belonging to CCI Groups 0 and 1 .

\begin{tabular}{|c|c|c|c|c|c|c|c|c|}
\hline \multirow[b]{2}{*}{$<65$} & \multicolumn{2}{|c|}{ CCI Group 0} & \multicolumn{2}{|c|}{ CCl Group 1} & \multicolumn{2}{|c|}{ CCl Group 2} & \multicolumn{2}{|c|}{ CCI Group 3} \\
\hline & $\geq 65$ & $<65$ & $\geq 65$ & $<65$ & $\geq 65$ & $<65$ & $\geq 65$ & \\
\hline Median PFS (months) & 7.5 & 6.6 & 9.2 & 13.5 & 6.6 & 5.5 & 7.5 & 7.1 \\
\hline Median OS (months) & 19.0 & 44.0 & 17.0 & 16.0 & 11.0 & 10.0 & 13.0 & 10.0 \\
\hline One-year Survival (\%) & 66.0 & 58.3 & 67.0 & 63.1 & 49.3 & 35.0 & 26.6 & 38.9 \\
\hline Two-year Survival (\%) & 41.7 & 29.1 & 41.7 & 23.1 & 21.9 & 17.0 & 0.0 & 0.0 \\
\hline Three-year Survival (\%) & 33.4 & 29.1 & 23.8 & 5.0 & 10.9 & 0.0 & 0.0 & 0.0 \\
\hline
\end{tabular}




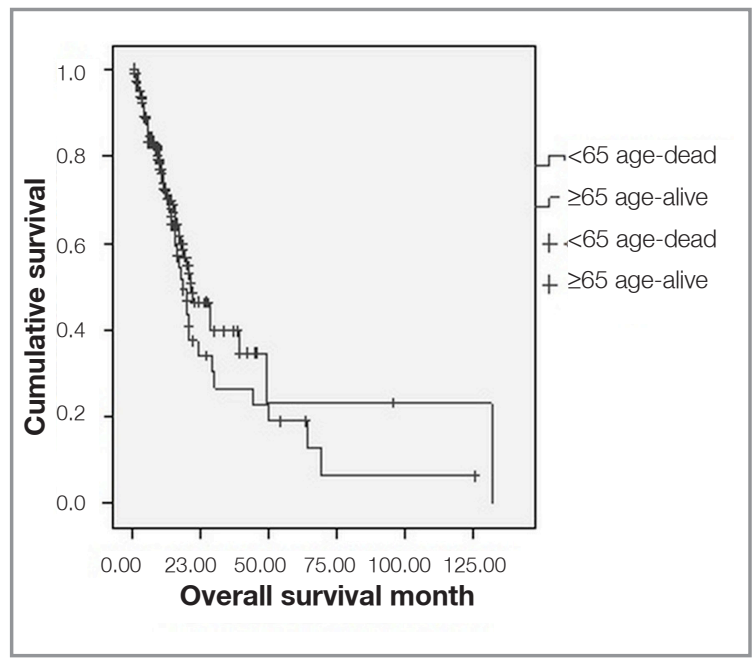

Figure 1. Overall survival of patients aged 65 and over and of patients under 65 years of age.

\section{Survival}

The median PFS for all of the patients was calculated to be 9.1 months with a median OS rate of 17.0 months. The one, two, and three-year survival rates for both patient age groups were $61.3 \%, 31.7 \%$, and $20.2 \%$, respectively. The group composed of those patients aged 65 and over had a median PFS of 9.7 months, a median OS of 15 months, and one, two, and three-year survival rates of $57.2 \%, 22.2 \%$, and $12.7 \%$. The corresponding rates for the younger group varied from the older age group patients with a median PFS of 8.6 months, a median OS of 18 months, and one, two, and three-year survival rates of $62.9 \%, 37.8 \%$, and $25.3 \%$.

When the survival parameters were assessed regarding the CCI groups, the median OS rates of the older and younger groups were as follows: 44 months versus 19 months for CCI Group 0, 16 months versus 17 months for CCI Group 1, 10 months versus 11 months for CCI Group 2, and 10 months versus 13 months for CCI Group 3 (Table 4).

There were no statistically significant differences concerning the effect of comorbidity factors on survival when the two patient groups were compared (Figure 1). Moreover, when assessed, survival was impacted by the effect of hypertension ; survival was shorter for patients who had this hypertension compared with those without hypertension. The median survival rate for those with hypertension was $17 \%$ with one, two, and three-year survival rates of $66 \%, 34.7 \%$, and $23.9 \%$. For those without hypertension, the median survival rate was 11 months with one, two, and three-year survival rates of $45.4 \%, 22.1 \%$, and $7 \%$.

\section{DISCUSSION}

This study provides further insight into the effect of medical comorbidities on the outcomes of advanced stage NSCLC such as chemotherapy related toxicities and survival rates. In this setting, we found that medical comorbidities occur frequently in advanced stage NSCLC and are associated with survival.

In our study, there was at least one comorbidity factor in $86 \%$ of the patients 65 years old or older, and the ratio was $62 \%$ for the patients under the age of 65. In both groups, regardless of the age, as the CCI scores increased, the therapy related toxicities also increased and a shorter survival duration was recorded. Cigarette-related comorbid factors were encountered much more frequently than others. The most commonly observed comorbidity factors were in decreasing order: chronic lung disease, diabetes, and coronary heart disease.

When lung carcinoma is encountered in later stages of life, various comorbidities usually accompany this disease. In a study conducted by D. MoroSibilotand et al., 588 patients with stage I and stage II NSCLC were examined, and the most common comorbid factors were as follows: chronic lung disease $(15.3 \%)$, peripheral venous disease $(13.4 \%)$, coronary heart disease $(12.7 \%)$, peptic ulcers $(10.7 \%)$, and diabetes mellitus $(6.3 \%) .{ }^{14}$ In a series of report analyses done by Janssen-Heijnen et al. in which 3864 lung carcinoma patient reports from the extensive population registry of the Eindhoven Cancer Center were reviewed, the most common comorbidities accompanying lung cancer in patients were found to be cardiovascular diseases (23\%) and chronic obstructive lung diseases (22\%), with other type of cancers making up the remainder $(15 \%) .{ }^{5} \mathrm{In}$ another study, Birim et al. evaluated 205 NSCLC patients, with $97 \%$ of those having been diagnosed as stage 1 , and found the most common accompanying comorbidity factors to be chronic lung disease $(37.1 \%)$, peripheral vascular disease $(25.9 \%)$, and coronary heart disease (22.9\%). ${ }^{15}$ In our study, $78.4 \%$ of all the patients in the study population had at least one accompanying comorbidity factor. This rate was considerably higher than that reported in 
many earlier studies, in which only $20 \%$ to $50 \%$ of patients had documented comorbidities. The reason for differences in comorbidity factors rates may be these previous studies include for the mostpart, patientswith early stage (Stage I-III) NSCLC. ${ }^{16-18}$ The prevalance of diabetes in our study was higher than that was found in similar, previous studies in the literature. There are conflicting data about the relationship between diabetes and incidence of NSCLC in the literature so that it is not possible to make a precise conclusion about this subject at this time. In a recently published meta-analysis of observational studies they showed that independently diabetes mellitus (DM) could increase the risk of lung cancer. ${ }^{18}$ In another meta-analysis they showed that patients with diabetes do not have an increased risk of lung cancer compared with their non-diabetic counterparts. ${ }^{19}$

With advancing age, there is deterioration in many organ and system functions, especially in the kidneys, liver, and bone marrow. This state of circumstances raises the potential for side effects associated with cytotoxic agents used in chemotherapies. ${ }^{20}$ For these reasons, there is a tendency to provide monotherapies as the choice of treatment in elderly patients. It was observed that weekly vinorelbine treatments were superior to special supplementary therapies in elderly patients. ${ }^{20}$ Similarly, it has also been reported that weekly docetaxel or paclitaxel monotherapies are superior to special supplementary therapies in elderly patients. ${ }^{20}$ When the studies, which have compared monotherapies with combined therapies in elderly patients with advanced stage lung carcinomas are reviewed, the efficiency increases with combined therapies, but this occurs at the expense of increased toxicity. ${ }^{20}$ In our study, monotherapy as the treatment of choice was much more common in the group of patients aged 65 years and over than in the patient groups under the age of 65 . With advancing age and high ratios of cigarette smoking, there is an increase in the frequency of comorbidities and toxicity due to chemotherapy. In elderly patients and those with a high number of comorbidity factors, single agent therapies can be preferable.

However, there are studies in literature that describe cases in which a choice of treatment based solely on age can be suboptimal with older patients possibly receiving inadequate treatment. ${ }^{21}$ In a study that assessed breast cancer patients over the age of 75 , it was reported that by evaluating comorbidity factors along with age, the rate of performing definitive locoregional therapy increased to $48.7 \% .^{22}$ In our study the hematologic toxicity rates were higher in CCI Group 0 and 1 patients aged 65 years and younger and receiving first line chemotherapy treatment. One reason for this may be that dual combination chemotherapy regimens more often used in younger age groups (CCI groups 0 and 1). In our study, there were more grade 3-4 hematologic and non-hematologic toxicities in CCI Group 2 and 3 for patients age 65 years and over than in the younger group. From this result we can say that as the CCI scores increased, the therapy related toxicities increased regardless of the age. These results show that when patients are being evaluated and decisions are being made about proper treatment, comorbid factors should also be kept in mind along with the age of the patient. Such an approach may aid in the tolerance to chemotherapy and anticipation of potential side effects, as well as, preventing suboptimal therapy being given to patients, thus helping make an optimal treatment choice for cancer patients. ${ }^{23}$

Also, there are studies in the literature that have investigated the correlation between survival duration, age and performance status. In a study conducted by Colinet et al, on 735 NSCLC patients mostly with stage III B - IV disease (70\%), the survival duration was less than expected. In that study, it was shown that comorbidity factors such as cardiovascular diseases, other malignities, diabetes, and alcohol consumption had no effect on survival, but chronic lung disease and renal failure were shown to decrease the survival duration in patients. Moreover, the patients were grouped according to the ECOG performance scale with one group having scores of $\geq 2$ and one with $<2$. The group with the performance scores of $\geq 2$ was found to have shorter survival times. ${ }^{24}$

In our study we showed that as the CCI group number increased, the survival time of patients both age groups decreased, but these results did not attain a statistically significant level. In similar studies in the literature, it was shown that survival rates decrease as the comorbidity factors increase, and this decrease was statistically significant in some studies. However, the majority of the patient groups selected in these studies were early stage (IA-IIIA) 
cancer patients. ${ }^{14,25-27}$ In one such study by Wang et al. conducted on NSCLC stage 1 patients who were followed up for five years following surgery, those with scores of 2 or higher in the CCI were found to have higher five-year survival rates than the patients with scores lower than $2 .{ }^{25}$ In another study conducted by D. Moro-Sibilot et al., patients were evaluated by means of the CCI, and it was reported that survival duration was shorter in patients with higher Charlson scores.$^{14}$ In the study by Firat et al. which included stage IIIA and IIIB NSCLC patients and which accepted comorbidity and the Karnofsky Performance Status (KPS) scale as prognostic factors, it was shown that the (KPS) and comorbidity scores affected survival durations. ${ }^{26}$ In the study by Birim et al., 433 NSCLC patients, $98 \%$ of whom had stage IA - IIIA disease, were assessed by means of the $\mathrm{CCI}$ and were divided into four groups by their CCI scores $(0,1-2,3-4$, and $\geq 5)$. The percentages of the patients in these four groups were as follows: CCI 0: $22 \%$, CCI 1-2: $55 \%$, CCI 3-4: $22 \%$, and CCI $\geq$ 5: $2 \%$. There were no statistically significant correlations between gender and histopathologic type and the survival rates in the patients; however, the survival rate in patients over 70 years old decreased. In the analysis performed with regard to the CCI groups, the survival duration was less in the group with $\mathrm{CCI} \geq 3$ than in the group with CCI $1-2 .{ }^{27}$ In a further study by Wang et al., the comorbidity status of the patients was assessed by means of the CCI and the Kaplan-Feinstein index (KFI). The Charlson groups were classified as 0,1 , and $\geq 2$. The KFI groups was classified as $0,1,2$, and 3 . The study claimed that an increase in the CCI scores had an effect on the patients' five-year survival rates, but no correlation was found between an increase in the KFI scores and the fluctuation in survival duration. ${ }^{25}$

Patients with comorbidities have an increased likelihood of experiencing treatment-related adverse effects in addition to exacerbations of the comorbidity..$^{28-30}$

Because of the adverse effects, these individuals might also be less likely to complete the prescribed chemotherapy treatment and because of this lower rates of disease control are obtained. ${ }^{31}$ Also, severe comorbidities might themselves limit life expectancy independent of the underlying malignancy. ${ }^{32,33}$

The principal limitations of our study include its retrospective single-center setting, relatively small sample size evaluating only the advanced stage (IIIB and IV) disease. Results in our study do not a demonstrate statistical significance between comorbidity factors and survival rates but this may be due to the limitations of our study.

In our study, hypertension, a frequent and important comorbidity encountered in the elderly which is not included in the CCI criteria, was independently assessed. It was seen that the survival duration was shortened in patients who had accompanying hypertension. Observational studies have demonstrated or revealed inconsistent results in demonstrating an association between blood pressure and cancer incidence and mortality. There are only a few observational studies in the literature evaluating any association of blood pressure and cancer mortality, which again shows inconsistent findings..$^{34,35}$

In a large study evaluating 7 European prospective cohorts the results suggested that a positive association was found between hypertension and cancer mortality. In this study the results suggest a small increased cancer risk overall in men with elevated blood pressure level and a higher risk for cancer death in men and women. For death from cancer specific sites among men, a significant positive association for hypertension was shown for oropharynx, rectum, pancreas, lung, prostate, bladder, and kidney cancers. ${ }^{36}$ In the literature there are inconsistent findings about the cancer mortality and incidence associated with hypertension in colon, breast, lung, and prostate cancer. ${ }^{37-42}$

Further studies are needed to investigate the potential role for high BP in tumor initiation, progression, survival outcomes in lung cancer.

Various medical comorbidities are frequent in NSCLC patients, and are significantly higher than in other common malignancies. It is not clear to what extent these comorbid conditions affect treatment selection and patient overall survival. ${ }^{43}$ From the results of our study and in conclusion, we can say that the existence of comorbid factors have a negative effect on survival durations while increasing the risk of therapy-related toxicities. The patient's age alone does not have a significant effect on survival duration, and toxicity rates. Due to these facts, comorbid factors should be kept in mind while planning therapy for elderly patients, and optimal therapy planning should be performed for each patient individually. 


\section{REFERENCES}

1. Chan SK, Gullick WJ, Hill ME. Mutations of the epidermal growth factor receptor in non-small cell lung cancer: search and destroy. Eur J Cancer 42: 17-23, 2006.

2. Spigel DR, Greco FA. Chemotherapy in metastatic and locally advanced non-small cell lung cancer. Semin Surg Oncol 21: 98-110, 2003.

3. Fried LP, Bandeen-Roche K, Kasper JD, Guralnik JM. Association of comorbidity with disability in older women: the Women's Health and Aging Study. J Clin Epidemiol 52: 2737, 1999.

4. Janssen-Heijnen ML, Smulders S, Lemmens VE, et al. Effect of comorbidity on the treatment and prognosis of elderly patients with non-small cell lung cancer. Thorax 59: 602-607, 2004.

5. Janssen-Heijnen ML, Schipper RM, Razenberg PP, et al. Prevalence of co-morbidity in lung cancer patients and its relationship with treatment: a population-based study. Lung Cancer 21,105-13, 1998.

6. Tammemagi CM, Neslund-Dudas C, Simoff M, Kvale P. Impact of comorbidity on lung cancer survival. Int J Cancer 103: 792-802, 2003.

7. Charlson ME, Pompei P, Ales KL, MacKenzie CR. A new method of classifying prognostic comorbidity in longitudinal studies: development and validation. J Chronic Dis 40: 373383, 1987.

8. Extermann M, Overcash J, Lyman GH, et al. Comorbidity and functional status are independent in older cancer patients. J Clin Oncol 16: 1582-1587, 1998.

9. Greenfield S, Blanco DM, Elashoff RM, Ganz PA. Patterns of care related to age of breast cancer patients. JAMA 257: 2766-2770, 1987.

10. Imamura K, McKinnon M, Middleton R, Black N. Reliability of a comorbidity measure: the Index of Co-Existent Disease (ICED). J Clin Epidemiol 50: 1011-16, 1997.

11. Kaplan MH, Feinstein AR. The importance of classifying initial co-morbidity in evaluatin the outcome of diabetes mellitus. J Chronic Dis 27: 387-404, 1974.

12. Linn BS, Linn MW, Gurel L. Cumulative illness rating scale. J Am Geriatr Soc 16: 622-626, 1968.

13. Abali $\mathrm{H}$, Ata A, Ozdogan M, et al. Frequency of comorbid illnesses in cancer patients in Turkey. J BUON 16: 557-560, 2011.

14. Moro-Sibilot D, Aubert A, Diab S, et al. Comorbidities and Charlson score in resected stage I nonsmall cell lung cancer. Eur Respir J 26: 480-486, 2005.

15. Birim O, Maat AP, Kappetein AP, et al. Validation of the Charlson comorbidity index in patients with operated primary nonsmall cell lung cancer. Eur J Cardiothorac Surg 23: 30-34, 2003.

16. Earle CC, Venditti LN, Neumann PJ, et al. Who gets chemotherapy for metastatic lung cancer? Chest 117: 1239-46, 2000.

17. Asmis TR, Ding K, Seymour L, et al. Age and comorbidity as independent prognostic factors in the treatment of non small-cell lung cancer: a review of National Cancer Institute of Canada Clinical Trials Group trials. J Clin Oncol 26: 54-59, 2008.
18. Lee J-Y, Jeon I, Lee JM, et al. Diabetes mellitus as an independent risk factor for lung cancer: a meta-analysis of observational studies. Eur J Cancer 49: 2411-2423, 2013.

19. Wang Z, Bao C, Su C, et al. Association between diabetes or antidiabetic therapy and lung cancer: A meta-analysis. J Diabetes Investig 27: 659-666, 2013.

20. Weinmann M, Jeremic B, Bamberg M, Bokemeyer C. Treatment of lung cancer in elderly part II: small cell lung cancer. Lung Cancer 40: 1-16, 2003.

21. Yancik R, Yates JW, Cumberlin R. Research recommendations for Radiation therapy in older cancer patients. Report from the National Institute on Aging, National Cancer Institute, and American College of Radiology Workshop: Radiation therapy and cancer in older persons. Int J Radiat Oncol Biol Phys 43: 3-5, 1999.

22. Hébert-Croteau N, Brisson J, Latreille J, et al. Compliance with consensus recommendations for the treatment of early stage breast carcinoma in elderly women. Cancer 85: 11041113, 1999.

23. Hall WH, Jani AB, Ryu JK, et al. The impact of age and comorbidity on survival outcomes and treatment patterns in prostate cancer. Prostate Cancer Prostatic Dis 8: 22-30, 2005.

24. Colinet B, Jacot W, Bertrand D, et al. A new simplified comorbidity score as a prognostic factor in non-small-cell lung cancer patients: description and comparison with the Charlson's index. Br J Cancer 93: 1098-1105, 2005.

25. Wang CY, Lin YS, Tzao C, et al. Comparison of Charlson comorbidity index and Kaplan-Feinstein index in patients with stage I lung cancer after surgical resection. Eur J Cardiothorac Surg 32: 877-878, 2007.

26. Firat S, Bousamra M, Gore E, Byhardt RW. Comorbidity and KPS are independent prognostic factors in stage I non-smallcell lung cancer. Int J Radiat Oncol Biol Phys 52: 1047-1057, 2002.

27. Birim O, Kappetein AP, Bogers AJ. Charlson comorbidity index as a predictor of long-term outcome after surgery for nonsmall cell lung cancer. Eur J Cardiothorac Surg. 28: 759762, 2005.

28. Pal SK, Hurria A. Impact of age, sex, and comorbidity on cancer therapy and disease progression. J Clin Oncol 28: 40864093, 2010.

29. Farjah F, Wood DE, Varghese TK, et al. Health care utilization among surgically treated Medicare beneficiaries with lung cancer. Ann Thorac Surg 88: 1749-1756, 2009.

30. Lee L, Cheung WY, Atkinson E, et al. Impact of comorbidity on chemotherapy use and outcomes in solid tumors: a systematic review. J Clin Oncol 29: 106-117, 2011.

31. Frasci G, Lorusso V, Panza N, Krzyzanowska MK. Gemcitabine plus vinorelbine versus vinorelbine alone in elderly patients with advanced non-small-cell lung cancer. J Clin Oncol 18: 2529-2536, 2000.

32. Piccirillo JF, Tierney RM, Costas I, et al. Prognostic importance of comorbidity in a hospital-based cancer registry. JAMA 291: 2441-2447, 2004.

33. Read WL, Tierney RM, Page NC, et al. Differential prognostic impact of comorbidity. J Clin Oncol 22: 3099-3103, 2004. 
International Journal of Hematology and Oncology

34. Grossman E, Messerli FH, Boyko V, Goldbourt U. Is there an association between hypertension and cancer mortality? Am J Med 112: 479-486, 2002.

35. Goon PK, Stonelake PS, Lip GY. Hypertension, anti-hypertensive therapy and neoplasia. Curr Pharm Des 13: 25392544, 2007.

36. Stocks T, Van Hemelrijck M, Manjer J, et al. Blood pressure and risk of cancer incidence and mortality in the Metabolic Syndrome and Cancer Project. Hypertension 59: 802-810, 2012.

37. Martin RM, Vatten L, Gunnell D, et al. Components of the metabolic syndrome and risk of prostate cancer: the HUNT 2 cohort, Norway. Cancer Causes Control 20: 1181-1192, 2009.

38. Giovannucci E. Metabolic syndrome, hyperinsulinemia, and colon cancer: a review. Am J Clin Nutr 86: 836-842, 2010.

39. Largent JA, McEligot AJ, Ziogas A, et al. Hypertension, diuretics and breast cancer risk. J Hum Hypertens 20: 727-732, 2006

40. Beebe-Dimmer JL, Dunn RL, Sarma AV, et al. Features of the metabolic syndrome and prostate cancer in African-American men. Cancer 109: 875-881, 2007.

41. Lindgren A, Pukkala E, Tuomilehto J, Nissinen A. Incidence of breastcancer among postmenopausal, hypertensive women. Int J Cancer 121: 641-644, 2007.

42. Lindgren A, Pukkala E, Nissinen A, Tuomilehto J. Blood pressure,smoking, and the incidence of lung cancer in hypertensive men in North Karelia, Finland. Am J Epidemiol 158: 442-447, 2003.

43. Ahn DH, Mehta N, Yorio JT, et al. Influence of medical comorbidities on the presentation and outcomes of stage I-III non-small-cell lung cancer. Clin Lung Cancer 14: 644-650, 2013.

\section{Correspondence}

Dr. Tulay AKMAN

Tepecik Eğitim ve Araştırma Hastanesi

Tıbbi Onkoloji Bölümü

Gaziler Caddesi, No: 468

Yenisehir, IZMiR / TURKEY

Tel: (+90.232) 4443560

Fax: (+90.232) 4330756

e-mail: tulaytuzel@gmail.com 